九州大学学術情報リポジトリ

Kyushu University Institutional Repository

Effects of Cultivation Temperature on the Growth and Saikosaponin Production of Bupleurum falcatum L. Cultivars

Son, Tae Kwon

1R\&D Center

Chung, Il Kyung

Department of Biotechnology, Catholic University of Daegu

Lee, Sang Chul

Division of Biosciences, College of Agriculture and Life Sciences, Kyungpook National University

Rico, Cyren M.

1R\&D Center

他

https://doi.org/10.5109/14032

出版情報：九州大学大学院農学研究院紀要. 54 (1)，pp.25-28，2009-02-27. Faculty of Agriculture， Kyushu University

バージョン :

権利関係 : 


\title{
Effects of Cultivation Temperature on the Growth and Saikosaponin Production of Bupleurum falcatum L. Cultivars
}

\author{
Tae Kwon SON ${ }^{1}$, Il Kyung CHUNG ${ }^{2}$, Sang Chul LEE ${ }^{3 *}$, \\ Cyren M. RICO ${ }^{1}$ and Mari IWAYA-INOUE
}

\author{
Laboratory of Crop Science, Department of Plant Resources, Faculty of Agriculture \\ Kyushu University, Fukuoka 812-8581, Japan \\ (Received November 13, 2008 and accepted December 5, 2008)
}

\begin{abstract}
The effects of cultivar and cultivation temperatures on root extract, ash content and saikosaponin content of Bupleurum falcatum L. were investigated using four Japanese and one Korean cultivars. Results showed that the Korean cultivar obtained higher root extract and saikosaponin contents but lower ash content than the Japanese cultivars at cultivation temperatures of $16.5-17.6{ }^{\circ} \mathrm{C}$. Higher cultivation temperature $\left(21.0^{\circ} \mathrm{C}\right)$ consistently yielded low values in all parameters for both cultivars. Results also showed inverse relationships between root extract and ash content, and between ash content and saikosaponin content. On the other hand, root extract showed direct relationship with saikosaponin content. This study indicated the usefulness of component analysis of plant materials for traditional medicinal preparation since each plant material may have different concentration of their active ingredients.
\end{abstract}

\section{INTRODUCTION}

Bupleurum falcatum L. (Ch'Ai Hu or MisimaSaiko) is a rich source of pharmacologically active saikosaponin (Park et al., 1992) which is used as an active ingredient in many drug preparations. Quality of $B$. falcatum is evaluated by mass content analysis of ash, extract, essential oil, saikosaponin concentration, etc. Higher values in these parameters indicate higher quality of $B$. falcatum. Thus, to increase secretion of saikosaponin in the B. falcatum roots has been a major focus of many scientific investigations.

Medicinal plant materials vary in quantity and quality depending on cultivation sites due to the influence of soil, climate and other factors (WHO, 2003). In B. falcatum, saikosaponin production and growth characteristics were found to be dependent on environmental and genetic factors (Shon et al., 1997a-c, 1998). Cultivation site was also shown to greatly influence production of pharmacologically active components in Aconitum roots (Hikino et al., 1983; Kitagawa et al., 1984). Besides, studies showed that cultivation temperature affects root growth and saikosaponin production of B. falcatum (Hosoda et al., 1992; Shimokawa and Ohashi, 1980; Otsuka et al., 1977; Shimokawa et al., 1980). In other medicinal plants, cultivation temperature also significantly affected growth and tuber productions of Aconitum carmichaelii Debx. (Shoyama et al., 1993; Shiping et al., 1998) and Arnebia benthamii (Wall. ex G. Don) (Kandari et al., 2008).

Although the effects of agronomic and environmen-

1 1R\&D Center, CU Tecno Park, Gyeongsan-si, Gyeongbuk, 712-702, Korea

2 Department of Biotechnology, Catholic University of Daegu, Gyeongsan-si, Gyeongbuk, 712-702, Korea

${ }^{3}$ Division of Biosciences, College of Agriculture and Life Sciences, Kyungpook National University, Daegu 702-701, Korea

* Corresponding author (E-mail: leesc@knu.ac.kr) tal factors on B. falcatum have been well explored already, studies on the effects of cultivar and cultivation temperature are still not fully conducted. Thus, this study investigated the effects of cultivar and cultivation temperature on the growth and saikosaponin production of B. falcatum.

\section{MATERIAL AND METHODS}

\section{Plant materials}

The experiment was carried out to determine the effect of genetic characteristics and environment factors on extract, ash and total saikosaponin contents of the root of $B$. falcatum. A total of five cultivars used were taken from Japan and Korea. Cultivars from Japan, Yasato, Nara, Mishima and Kumamoto, contained 26 chromosomes while the Korean cultivar contained 20 of them. These cultivars were planted in four different regions (A-1, A-2, A-3, and A-4) varying in the amount of precipitation and temperatures (Fig. 1). The average temperatures for the regions A-1 to A-4 were 21.0, 17.6, 16.9 and $16.5^{\circ} \mathrm{C}$, respectively. Besides them, two culti-

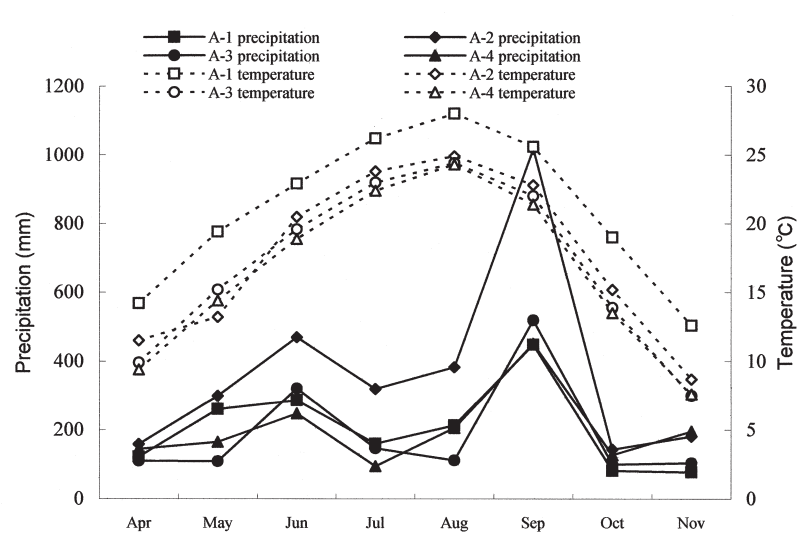

Fig. 1. Average amount of precipitation and temperature during the cultivation period of Bupleurum falcatum. 
vars of B. falcatum, originating from Korea and Japan, were grown at an experimental farm. Seeds were distributed from National Crop Experimental Station, Suwon, Korea and Tsukuba Medical Plant Research Station, National Institute of Health Sciences, Japan. Cultivation was carried out with the cultivation method of B. falcatum described by Shon et al. (1998). Sampling of plants was done in late November. Plant samples were air dried for one week and then stored in tight containers for analysis.

\section{Root extract analysis}

Root extract analysis was conducted according to the modified method of the Korean Herbal Pharmacopoeia (KFDA, 2006). Two to three grams of the sample was accurately weighed, extracted with $70 \%$ ethanol in a suitable flask with intermittent shaking for 5 hours, and allowed to stand for 20 hours. The solution was filtered and the flask was washed with a small amount of dilute ethanol to make $100 \mathrm{~mL}$ of filtrate. Fifty $\mathrm{ml}$ aliquot of the filtrate was evaporated to dryness, dried at $105^{\circ} \mathrm{C}$ for 4 hours, and cooled in a dessicator. The weight of the residue was measured and multiplied by 2 to determine the amount of dilute ethanol-soluble extract.

\section{Total ash content analysis}

Total ash analysis was done according to the modified method of the Korean Herbal Pharmacopoeia (KFDA, 2006). The platinum crucible was tared by placing in an oven with temperature between $500{ }^{\circ} \mathrm{C}$ for 1 hour. It was then cooled and weighed accurately. The sample ( $3 \mathrm{~g}$ ) was put in the crucible, heated at low temperature first, and gradually exposed to high temperature upto $550^{\circ} \mathrm{C}$, for more than 4 hours to ignite the sample until no carbonized substance remained in the ash. After the crucible was cooled down, the ash was accurately weighed. The procedure was repeated until constant weight was obtained and then amount (\%) of total ash was determined. The charred mass was added with hot water and the insoluble residue was collected on a filter paper which was incinerated until no carbonized substance remained in the ash. The filtrate was added and evaporated to dryness. After drying, the sample was incinerated as described above, cooled down and weighed accurately to determine the weight (\%) of the total ash.

\section{Saikosaponin content analysis}

Saikosaponin content was analyzed according to the modified method of Kimata et al. (1979). Two to three grams of the sample was accurately weighed, extracted with $70 \%$ ethanol in a suitable flask with intermittent shaking for 5 hours, and allowed to stand for 20 hours. The solution was filtered, and the flask was washed with a small amount of dilute ethanol to make until $100 \mathrm{~mL}$ of filtrate. Fifty $\mathrm{mL}$ aliquot of the filtrate was evaporated to dryness, dried at $105^{\circ} \mathrm{C}$ for 4 hours, and cooled in a desiccator. The weight of the residue was measured and multiplied by 2 to determine the amount of dilute ethanol-soluble extract.

\section{RESULTS AND DISCUSSION}

\section{Effect on the root extract}

The extraction rate of root extract did not follow the trend of temperature. The highest extraction rate of root extract (29.8\%) was of the Korean cultivar planted at the lowest temperature $\left(16.5^{\circ} \mathrm{C}\right)$ while the lowest extraction rate was of Yasato cultivar (20.8\%) at similar degree of low temperature $\left(16.9^{\circ} \mathrm{C}\right)$ (Table 1$)$. The highest extraction rate of root extract among those planted in the highest temperature was obtained in Mishima (25.8\%). The highest mean root extract across different cultivation temperatures was obtained in the Korea cultivar (25.6\%). Generally, higher extraction rate of root extracts were obtained in the regions A-2, A-3 and A-4 with low temperatures $\left(16.5-17.6^{\circ} \mathrm{C}\right)$. This result is in contrast to the reports by Fujii et al. (1994) which showed that culture solution of B. falcatum obtained the maximum saponin content at $25 / 25^{\circ} \mathrm{C}$ (photoperiod/dark period air temperature) and high efficiency in saponin production for 20 hour per day photoperiod.

Results also showed that B. falcatum harvested from the region $\mathrm{A}-3\left(16.9^{\circ} \mathrm{C}\right)$ obtained lower extraction rate of root extracts $(20.8-4.2 \%)$ compared to those from the regions $\mathrm{A}-2\left(17.6^{\circ} \mathrm{C}\right)$ and $\mathrm{A}-4\left(16.5^{\circ} \mathrm{C}\right)$ which ranged from 23.7-6.9 and 24.6-29.8\%, respectively. The extraction rate of root extract from the region $\mathrm{A}-3$ was also lower than those from the region A-1 (22.4-25.8\%). This could probably be due to very low amount of precipitation in A-3 (190.3 mm) compared to that in regions $\mathrm{A}-1$ (206.3 $\mathrm{mm}), \mathrm{A}-2(371.5 \mathrm{~mm})$ and A-4 (204.1 mm).

Table 1. Root extract of Bupleurum falcatum harvested from different cultivation temperatures

\begin{tabular}{cccccc}
\hline \multirow{2}{*}{$\begin{array}{c}\text { Cultivation } \\
\text { temperature* }\end{array}$} & \multicolumn{5}{c}{ Root extract (\%) } \\
\cline { 2 - 6 } & Yasato & Nara & Mishima & Kumamoto & Korea \\
\hline A-1 & $23.55 \pm 0.764$ & $23.17 \pm 0.749$ & $25.81 \pm 0.810$ & $23.18 \pm 0.264$ & $22.41 \pm 0.393$ \\
A-2 & $25.08 \pm 0.635$ & $23.67 \pm 0.688$ & $24.57 \pm 0.498$ & $26.93 \pm 0.067$ & $25.89 \pm 0.111$ \\
A-3 & $20.84 \pm 0.109$ & $23.00 \pm 0.273$ & $21.42 \pm 0.533$ & $21.04 \pm 0.590$ & $24.19 \pm 0.444$ \\
A-4 & $25.33 \pm 0.749$ & $24.61 \pm 0.167$ & $25.76 \pm 0.208$ & $25.59 \pm 0.248$ & $29.83 \pm 0.448$ \\
\hline Mean & $23.70 \pm 1.786$ & $23.613 \pm 0.626$ & $24.39 \pm 1.785$ & $24.185 \pm 2.259$ & $25.58 \pm 2.745$ \\
\hline
\end{tabular}

* Average cultivation temperature $\left({ }^{\circ} \mathrm{C}\right)$ : $\mathrm{A}-1=21.0, \mathrm{~A}-2=17.6, \mathrm{~A}-3=16.9, \mathrm{~A}-4=16.5$. 
Table 2. Ash content of Bupleurum falcatum harvested from different cultivation temperatures

\begin{tabular}{cccccc}
\hline \multirow{2}{*}{$\begin{array}{c}\text { Cultivation } \\
\text { temperature* }\end{array}$} & \multicolumn{5}{c}{ Ash content (\%) } \\
\cline { 2 - 6 } & Yasato & Nara & Mishima & Kumamoto & Korea \\
\hline A-1 & $0.66 \pm 0.021$ & $0.58 \pm 0.057$ & $0.51 \pm 0.057$ & $0.68 \pm 0.014$ & $0.50 \pm 0.026$ \\
A-2 & $0.87 \pm 0.120$ & $0.86 \pm 0.085$ & $0.73 \pm 0.025$ & $0.68 \pm 0.080$ & $0.52 \pm 0.055$ \\
A-3 & $0.50 \pm 0.078$ & $0.59 \pm 0.033$ & $0.56 \pm 0.052$ & $0.53 \pm 0.084$ & $0.57 \pm 0.045$ \\
A-4 & $0.96 \pm 0.082$ & $0.72 \pm 0.066$ & $0.79 \pm 0.036$ & $0.66 \pm 0.045$ & $0.42 \pm 0.056$ \\
\hline Mean & $0.75 \pm 0.180$ & $0.69 \pm 0.114$ & $0.65 \pm 0.116$ & $0.64 \pm 0.063$ & $0.50 \pm 0.054$ \\
\hline
\end{tabular}

* Average cultivation temperature $\left({ }^{\circ} \mathrm{C}\right)$ : $\mathrm{A}-1=21.0, \mathrm{~A}-2=17.6, \mathrm{~A}-3=16.9, \mathrm{~A}-4=16.5$.

Table 3. Saikosaponin content of root of Bupleurum falcatum harvested from different cultivation temperatures

\begin{tabular}{cccccc}
\hline \multirow{2}{*}{$\begin{array}{c}\text { Cultivation } \\
\text { temperature* }\end{array}$} & \multicolumn{5}{c}{ Saikosaponin content $(\mathrm{mg} / \mathrm{g})$} \\
\cline { 2 - 5 } & Yasato & Nara & Mishima & Kumamoto & Korea \\
\hline A-1 & $0.98 \pm 0.180$ & $0.92 \pm 0.230$ & $1.21 \pm 0.300$ & $0.94 \pm 0.350$ & $1.38 \pm 0.290$ \\
A-2 & $1.40 \pm 0.523$ & $1.50 \pm 0.320$ & $1.89 \pm 0.460$ & $1.22 \pm 0.460$ & $2.91 \pm 0.640$ \\
A-3 & $1.89 \pm 0.630$ & $1.22 \pm 0.230$ & $2.23 \pm 0.610$ & - & $1.34 \pm 0.330$ \\
A-4 & $1.61 \pm 0.070$ & $1.90 \pm 0.570$ & $2.24 \pm 0.050$ & $1.83 \pm 0.90$ & - \\
\hline Mean & $1.47 \pm 0.332$ & $1.39 \pm 0.361$ & $1.89 \pm 0.418$ & $1.33 \pm 0.372$ & $1.78 \pm 0.589$ \\
\hline
\end{tabular}

* Average cultivation temperature $\left({ }^{\circ} \mathrm{C}\right)$ : $\mathrm{A}-1=21.0, \mathrm{~A}-2=17.6, \mathrm{~A}-3=16.9, \mathrm{~A}-4=16.5$.

\section{Effect on the root ash content}

The effect of cultivation temperature on ash content of B. falcatum root was investigated (Table 2). Ash content can be a measure of root growth. The Yasato cultivar obtained high production rate of ash contents in the regions A-2 (0.87\%) and A-4 (0.96\%). The Korean cultivar obtained lower ash content compared with that of the Japanese cultivars except in the region A-3. Also, ash content of cultivars harvested from the region A-3 obtained lower values compared with that harvested from the other regions. This trend was similar with the root extract.

Studies showed varying effects of temperature on root yield. Shimokawa et al. (1990) reported increasing root yield at lower temperature. On the contrary, Hosoda and Noguchi (1992) reported increasing root yield at higher temperature. Shimokawa et al. (1990) reported that root growth favored temperature $\left(15 / 10^{\circ} \mathrm{C}\right.$ day/night) while decreased root growth was observed at higher temperature $\left(35 / 30{ }^{\circ} \mathrm{C}\right.$ day/night). Shoyama et al. (1993) reported increased number of leaves and flowers at higher temperature and promotion of tuber production at lower temperature at in vitro experiments.

Furthermore, the results did not show a consistent trend that observed in the root extract. The Korean cultivar obtained lower ash content than other four Japanese cultivars. It can be said that root extract is inversely related to ash content of $B$. falcatum root.

\section{Effect on the saikosaponin content}

Table 3 shows the effect of cultivation temperature on saikosaponin contents in B. falcatum root. The Korean cultivar planted in the region A-2 $\left(17.6^{\circ} \mathrm{C}\right)$ obtained the highest saikosaponin content of $2.61 \mathrm{mg} / \mathrm{g}$. This was followed by Mishima cultivar planted at the lowest cultivation temperature, producing $2.24 \mathrm{mg} / \mathrm{g}$. The other Japanese cultivars obtained relatively lower saikosaponin contents whether planted in lower or higher cultivation temperatures. Shimokawa et al. (1980) reported that only little difference was observed in the saikosaponin content of $B$. falcatum cultivated at different temperature conditions. The same was observed in this experiment for both Japanese and Korean cultivars.

\section{CONCLUSION}

Results showed that, at lower cultivation temperature $\left(16.5-17.6^{\circ} \mathrm{C}\right)$, the Korean cultivar obtained higher extraction rate of root extract and saikosaponin contents than the Japanese cultivars. As for cultivation temperature, the Japanese cultivars obtained lower extraction rate of root extract, higher production rate of ash content and lower saikosaponin content, except Mishima cultivar, which had seen increase saikosaponin contents. Higher cultivation temperature $\left(21.0^{\circ} \mathrm{C}\right)$ consistently yielded low values in all parameters for both cultivars. Results also showed inverse relationships between the root extract and ash content, and between ash content and saikosaponin content. On the other hand, root extract showed direct relationship with saikosaponin content. This study indicated the usefulness of component analysis of plant materials for traditional medicinal preparation since each plant material may have different concentration of their active ingredients. 


\section{ACKNOW LEDGMENT}

We would like to than Ms. H. Ishioka and Ms. M. Kawaguchi for formatting and Ms. K. Inoue for proofreading.

\section{REFERENCES}

Fujii R., Y. Nagaoka and H. Watanabe 1994 Solution culture of Bupleurum falcatum for the purpose of accumulation of saikosaponins in the leaves: effects of environmental factors on plant growth and saikosaponin production. Environ. Control Biol., 32: 219-224

Hosoda K., M. Noguchi, Y. Hisata and Y. Noro 1992 Studies on the cultivation of Bupleurum falcatum L. III: Effect of soil ventilation on the root morphology. Shoyakugaku Zasshi, 47: $17-21$

Hikino H., M. Murakami, C. Konno and H. Watanabe 1983 Determination of aconitine alkaloids in Aconitum root. Planta Medica, 48: 67-71

Kandari L. S., K. S. Rao, R. K. Maikhuri and K. Chauhan 2008 Effect of pre-sowing, temperature and light on the seed germination of Arnebia benthamii (Wall. ex G. Don): An endangered medicinal plant of Central Himalaya, India. African J. Plant Sci., 2: 5-11

KFDA 2006 Korean Herbal Pharmacopoeia

Kimata, H., C. Hiyama, S. Yahara, O. Tanaka, O. Ishikawa and M. Aiura 1979 Application of high performance liquid chromatography to the anlysis of crude drugs: separatory determination of saponins of Bupleuri Radix. Chem. Pharm. Bull., 27: 1836-1841

Kitagawa I., Z. L. Chen, M. Yoshihara and M. Yoshikawa 1984 Chemical studies on crude drug processing IV. Aconit tuber (3). Quatitative determination of aconitine alkaloids in aconiti tuber by means of high performance liquid chromatography. Yakugaku Zasshi, 104: 867-872
Otsuka H., S. Kobayashi and S. Shibata 1977 Studies on the cultivation of Bupleurum falcatum L. (Mshimasaiko). Shoyakugaku Zasshi, 31: 195-197

Shimokawa Y. and H. Ohashi 1980 Cultivation and breeding of Bupleurum falcatum L. (V) - Relation among cultivation years, root growth and saikosaponin content. Shoyakugaku Zasshi, 34: 235-238

Shimokawa Y., N. Ushio, N. Uno and H. Ohashi 1980 Cultivation and breeding of Bupleurum falcatum L. (I) Effect of temperature on growth, development and saikosaponin content of one-year-old plants. Shoyakugaku Zasshi, 34: 209-214

Shiping C., S. J. Shan, H. Tanaka and Y. Shoyama 1998 Effects of culture temperature on microtuber formation of Acotinum carmichaelii Debx. and aconitine-type alkaloid contents. Biotronics, 27: 15-20

Shon T. K., A. D. H. Totok and T. Yoshida 1997a Variation and distribution of saikosaponin in Bupleurum falcatum L., J. Fac. Agr. Kyushu Univ., 42: 17-22

Shon T. K. and T. Yoshida 1997b Induction of haploid plantlets by anther culture of Bupleurum falcatum L. Jpn. J. Crop. Sci, 6 6: $137-138$

Shon T. K., A. D. H. Totok and T. Yoshida 1997c Dry matter production and utilization of solar energy in one-year-old Bupleurum falcatum. J. Fac. Agr. Kyushu Univ., 41: 133-139

Shon T. K., A. D. H. Totok and T. Yoshida 1998 Studies on dry matter production and efficiency for solar energy utilization in Bupleurum falcatum L. at different plant ages. Plant Prod. Sci., 1: 113-118

Shoyama Y., Y. Yamada and I. Nishioka 1993 Relationship between the content of aconitine-type alkaloids and growth environments in clonally propagated Aconitum carmichaelii Debx. Biotronics, 22: 87-93

WHO 2003 World Health Organization guidelines on good agri cultural and collection practices (GACP) for medicinal plants 